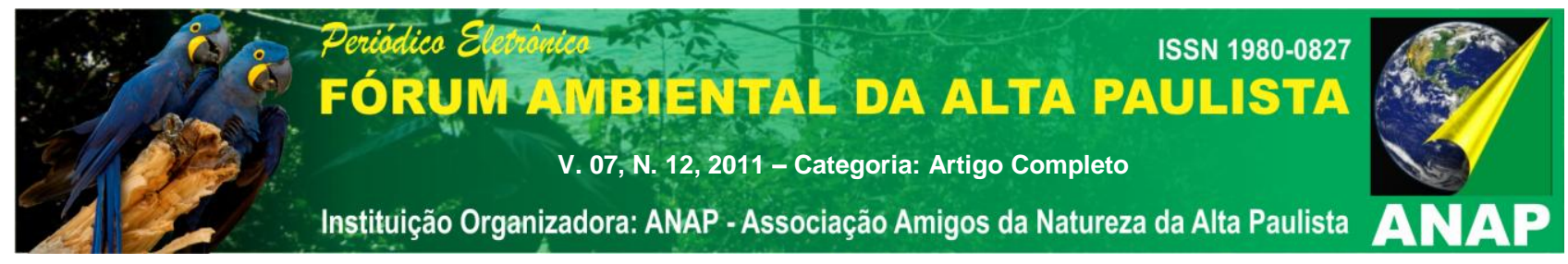

\title{
CONSTRUÇÃO DE UMA ESTAÇÃO DE TRATAMENTO DE ESGOTO NA UNESP DE BAURU/SP UTILIZANDO O SISTEMA DE ALAGADOS CONSTRUÍDOS
}

\author{
Maria Clara Godinho Somer Avelino ${ }^{1}$ \\ Eduardo Luiz de Oliveira ${ }^{2}$ \\ Thais Von Dreifus ${ }^{3}$ \\ Larissa Miranda-Santos ${ }^{4}$
}

Resumo: O objetivo deste estudo foi projetar e construir uma Estação de Tratamento de Esgoto para tratar parte do esgoto sanitário produzido na Universidade Estadual Paulista - UNESP de Bauru/SP. O método de tratamento proposto é formado por um sistema hibrido de alagados construídos de fluxo subsuperficial horizontal e vertical. A ETE foi projetada para atender inicialmente cerca de 400 pessoas e foi construída no campus do Departamento de Educação Física. A construção teve duração de cinco meses e o custo de implantação do sistema ficou dentro do previsto no projeto.

Palavras-chave: alagados construídos, tratamento de esgoto sanitário, construção de ETE.

\section{INTRODUÇÃO}

Dentre os recursos naturais fundamentais, a água é o que apresenta maior destaque, pois sua disponibilidade é necessária a todo tipo de vida no planeta, bem como à maioria dos meios de produção. A disponibilidade de água significa não somente que ela está presente em quantidade, mas também que sua qualidade é satisfatória para suprir as necessidades de um determinado conjunto de seres vivos. O uso da água pelo 


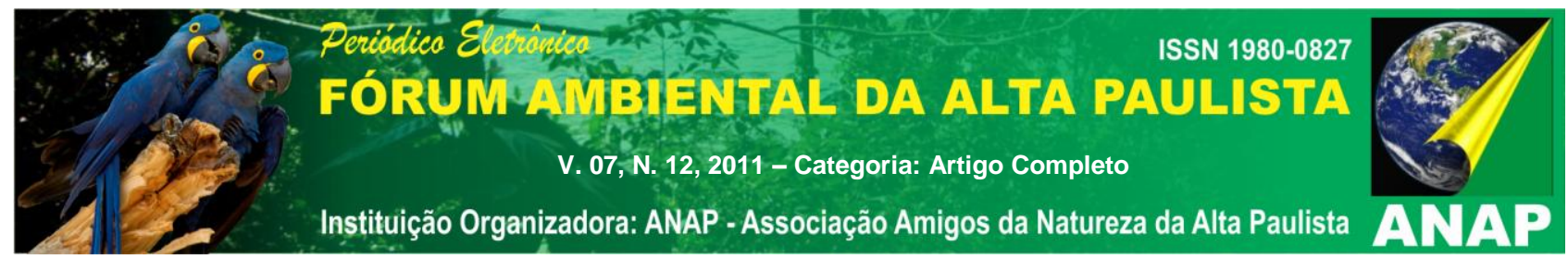

ser humano, para qualquer finalidade, resulta na deterioração da sua qualidade, limitando, geralmente, seu potencial de uso, que, no entanto, deve ser respeitado nos termos da legislação que estabelece os padrões de lançamento de efluentes em corpos d'água. (SARDINHA et al., 2008).

Além do prejuízo ambiental, causado pelo despejo de efluentes sanitários de forma indiscriminada no meio ambiente, têm-se os graves problemas de saúde pública e de cidadania gerados pelo déficit em saneamento básico (GALVÃO JUNIOR et al., 2009). De acordo com o relatório mundial de saúde da Organização Mundial da Saúde (OMS), estima-se que, em 2007, existiam cerca de 1,1 bilhão de pessoas sem acesso a água segura e 2,6 bilhões sem saneamento adequado. (Organização Mundial da Saúde, 2007).

No Brasil, o déficit do setor de saneamento básico é elevado, sobretudo no que se refere ao esgotamento sanitário, com maior carência nas áreas periféricas dos centros urbanos e nas zonas rurais, onde se concentra a população mais pobre. (GALVÃO JUNIOR et al, 2009).

Segundo IBGE, 2010 no ano de 2008, pouco mais da metade dos municípios brasileiros $(55,2 \%)$ tinha serviço de esgotamento sanitário por rede coletora, que é o sistema apropriado, marca pouco superior à observada na pesquisa anterior, realizada em 2000, que registrava 52,2\%. Em 2008, a proporção de municípios com rede de coleta de esgoto foi bem inferior à de municípios com rede geral de distribuição de água (99,4\%), manejo de resíduos sólidos (100,0\%) e manejos de águas pluviais (94,5\%).

Os alagados construídos são ecossistemas artificiais que, com diferentes tecnologias e plantas, utilizam os princípios básicos de qualidade da água dos alagados naturais. Conforme Oliveira et al. (2005), os alagados construídos, ao contrário dos naturais, podem ser usados, deliberadamente, como sistemas de tratamento de águas residuárias, sem que haja a constante preocupação com a performance e eficiência do processo, no sentido de minimizar os efeitos que as descargas de efluentes possam trazer ao ecossistema. Isto porque no ambiente construído o grau de controle é muito maior, permitindo que a experimentação com relação à composição do substrato, tipo de 


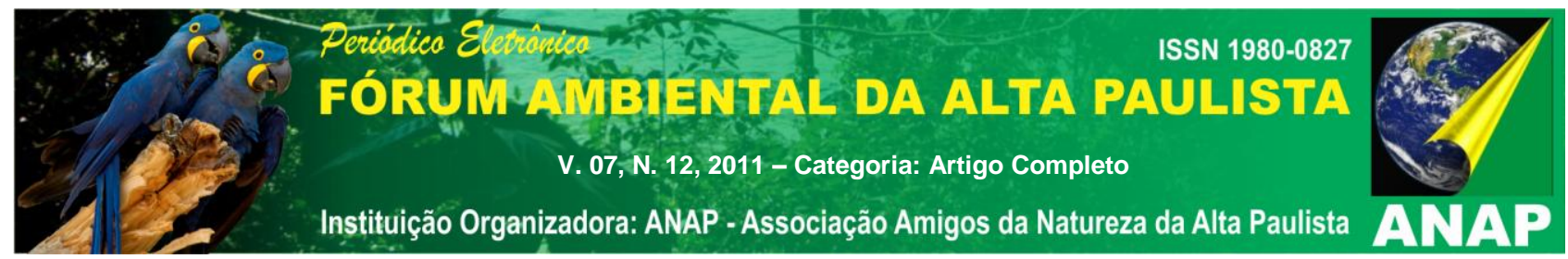

vegetação, padrão de fluxo, tempo de retenção e procedimento hidráulico conduzam a melhor eficiência e desempenho do processo de tratamento.

Kadlec \& Knight (1996 apud EPA, 2000) citam que a utilização de áreas alagadas naturais apresenta um bom histórico no tratamento de águas residuárias, provavelmente esse tipo de ecossistema vem sendo usado para o escoamento de esgoto desde 1912. Porem os estudos sobre a utilização de alagados construídos para o tratamento de esgoto começou na Europa na década de 1950 e nos Estados Unidos no final da década de 1960 (EPA, 2000).

Com o intuito de dar uma destinação adequada ao esgoto sanitário gerado no campus de Educação Física da Universidade Estadual Paulista - Unesp de Bauru/SP e também criar um espaço que possibilite o desenvolvimento de pesquisas cientificas, 0 presente projeto propôs a construção de uma Estação de Tratamento de Esgoto que utiliza um sistema hibrido de alagados construídos como parte do tratamento biológico do esgoto gerado no campus.

\section{DESENVOLVIMENTO}

\section{2 Área de Estudo}

O campus do departamento de Educação Física da UNESP de Bauru/SP fica separado dos outros departamentos pela rodovia Comandante João Ribeiro de Barros (SP-225) e está localizado na latitude 22²1'11,29" S e longitude 4901'42,91” O (Figura $1)$.

O município de Bauru situa-se no centro-oeste do estado de São Paulo, possui uma área de $673,5 \mathrm{Km}^{2}$ e uma população estimada de 359.429 habitantes, sendo cerca de $95 \%$ considerada urbana (IBGE, 2010). 

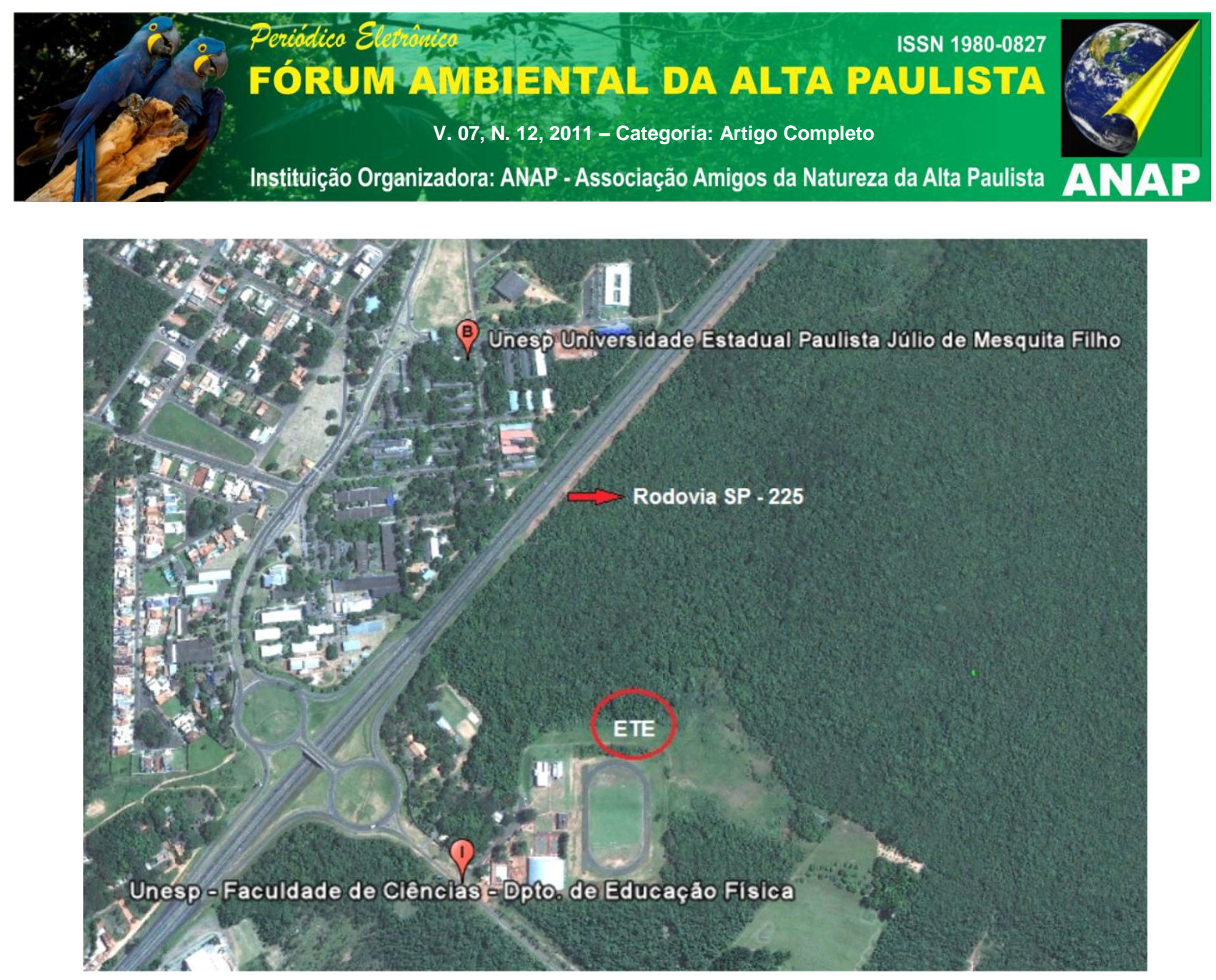

Figura 1. Localização da Área de Estudo.

O Departamento de Educação Física é frequentado por 277 alunos, 43 docentes e 3 funcionários, gerando uma vazão estimada de 10 mil litros de esgoto por dia. No momento encontra-se em construção a Moradia Estudantil que pretende atender 64 alunos da Universidade no ano de 2012, futuramente a ETE deverá incorporar também o esgoto sanitário produzido no local.

\subsection{Descrição do Projeto}

Atualmente, todo esgoto gerado no Departamento é encaminhado a fossas negras, sistema de destinação para águas residuárias quando não há alternativa, entretanto esse método pode causar poluição dos recursos subterrâneos se não operado adequadamente. 


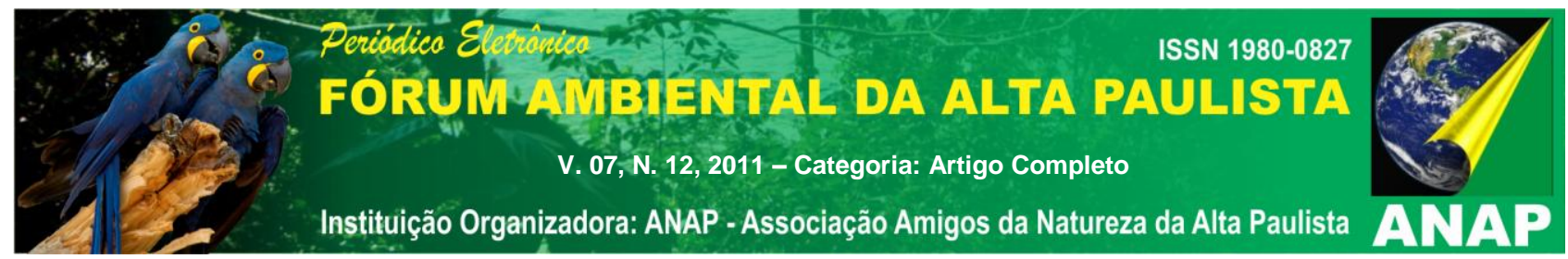

Para isso foi projetada a Estação de Tratamento de Esgoto (ETE) que utiliza o sistema de alagados construídos como parte do processo biológico de tratamento do esgoto (Figura 2). A ETE é composta por quatro etapas de tratamento (preliminar, primário, secundário e terciário).

a) Tratamento preliminar: Esta etapa do tratamento compreende um sistema de gradeamento responsável por reter sólidos grosseiros, uma peneira estática hidrodinâmica com a finalidade de reter sólidos mais finos que possam causar entupimentos no sistema e uma caixa de distribuição com três divisórias para distribuição do efluente nos três alagados de fluxo horizontal.

b) Tratamento primário: O tratamento primário é composto por uma fossa séptica, que se destina à remoção de sólidos em suspensão sedimentáveis e sólidos flutuantes; consequentemente, uma parcela da matéria orgânica em suspensão contida no esgoto fica retida nessa etapa do tratamento. A fossa séptica possui capacidade para 5.500 litros.

c) Tratamento secundário: Esta fase é constituída por três leitos de alagados construídos de fluxo horizontal que visam, especialmente, à remoção da DBO e de SST. Os leitos possuem dimensões de $9,0 \times 4,5 \mathrm{~m}$ e utiliza diferentes materiais como substrato, tais como, areia grossa, pedra $n \div 0$, pedra $n \div 1$, pedra $\mathrm{n}-3$ e poliestireno expandido (isopor) moído.

d) Tratamento terciário: O tratamento terciário é uma etapa adicional de tratamento, formada por três leitos de alagados construídos de fluxo vertical, com recirculação, que tem o objetivo de melhorar o processo de nitrificação do sistema, reduzindo assim a quantidade de nitrogênio amoniacal. O conjunto de ACFVR conta com três leitos de 3,2 x 3,2 m cada um, com profundidade de 0,80 m e declividade de $1 \%$ para garantir o escoamento do esgoto por gravidade, e os substratos utilizados são os mesmos usados nos alagados de fluxo horizontal. 

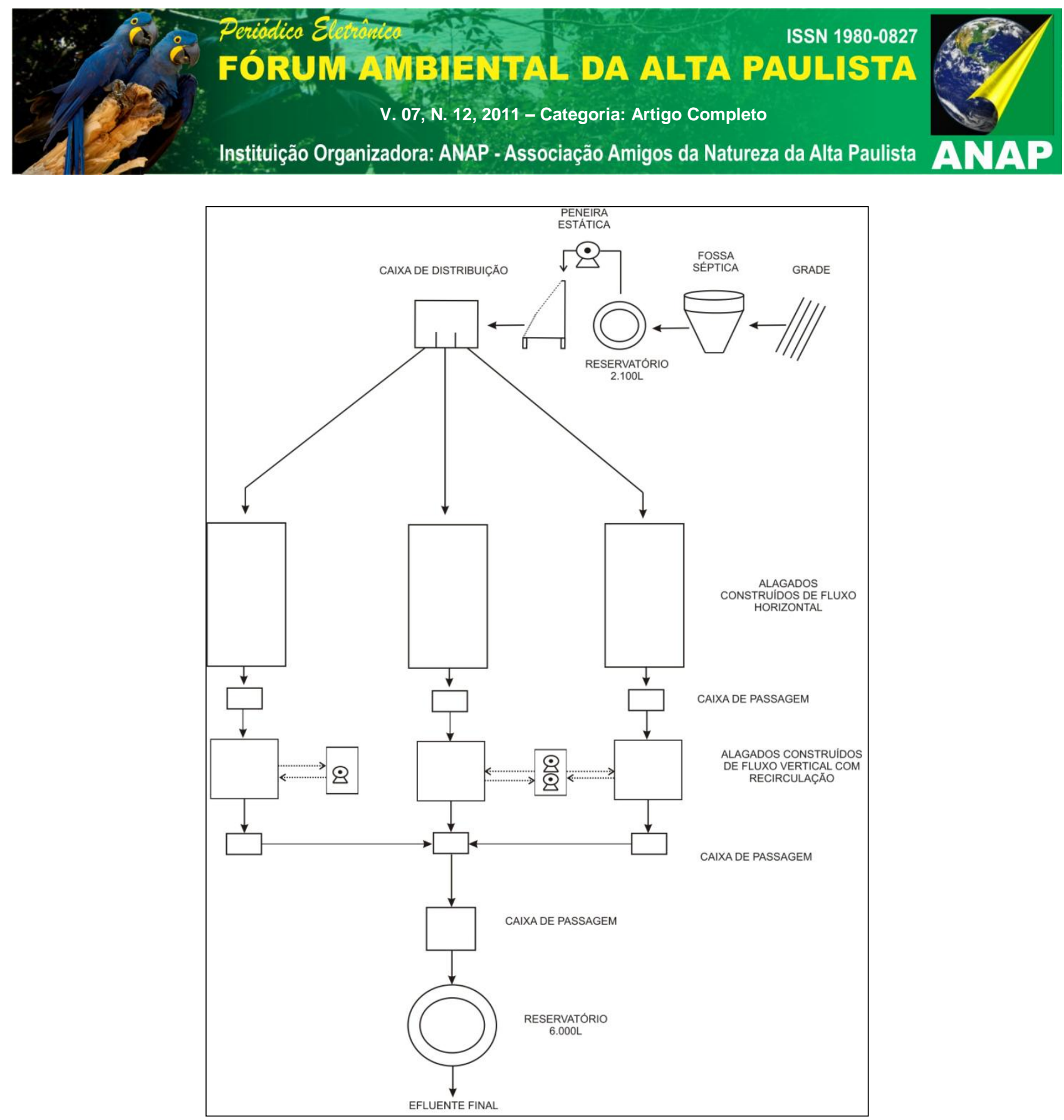

Figura 2. Esquema da Estação de Tratamento de Esgoto.

A planta escolhida para compor todos os leitos da ETE foi o capim Vetiver (Chrysopogon zizanioides), planta conhecida mundialmente pela eficiência no controle de erosão, estabilização de encostas e recuperação de áreas degradadas.

No Brasil, apesar de a produção de vetiver ainda ser pequena e haver poucos estudos sobre seus diversos usos, as perspectivas são animadoras em relação à utilização da planta no tratamento de águas residuárias.

Segundo Srivastava et al. (2008) pesquisas tem demonstrado uma enorme capacidade do capim vetiver em remover $\mathrm{N}$ e $\mathrm{P}$ de águas residuárias. $\mathrm{O}$ vertiver pode 


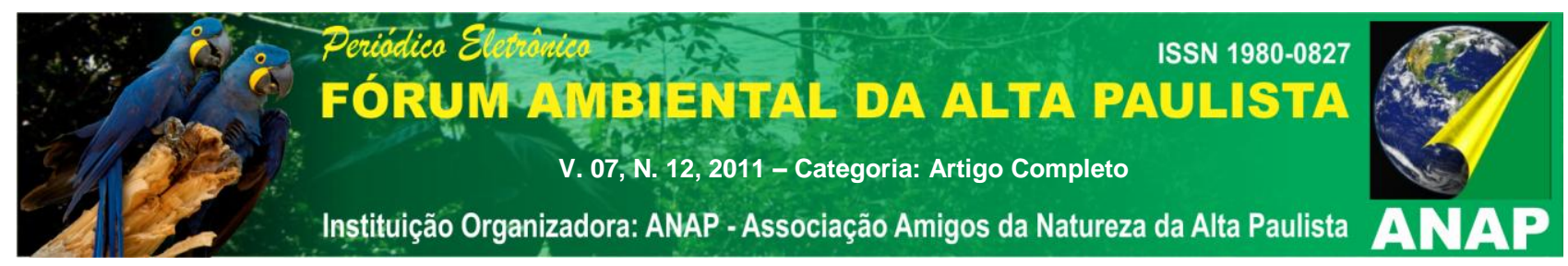

suportar taxas de N: $10.000 \mathrm{Kg}$ ha-1 ano-1 e P: 1.000ha-1 ano-1 (LAVANIA et al., 2004 apud SRIVASTAVA et al., 2008).

Diante dessas considerações, acreditamos que o capim vetiver apresente resultados satisfatórios quando utilizado nos alagados construídos.

Após a definição do projeto, foi realizado um levantamento prévio do custo para implantação do sistema chegando a um valor de $\mathrm{R} \$ 94.066,85$. Vale ressaltar que se trata de um projeto de pesquisa, portanto, alguns itens que compõem o sistema fazem parte de testes que serão feitos e acabam por encarecer o projeto. Esses itens podem ser substituídos por opções de menor valor se houver necessidade.

\subsection{Construção}

A execução da obra teve início no dia 12 de abril de 2011 com término no mês de setembro de 2011. As etapas da construção representadas na figura 3. 

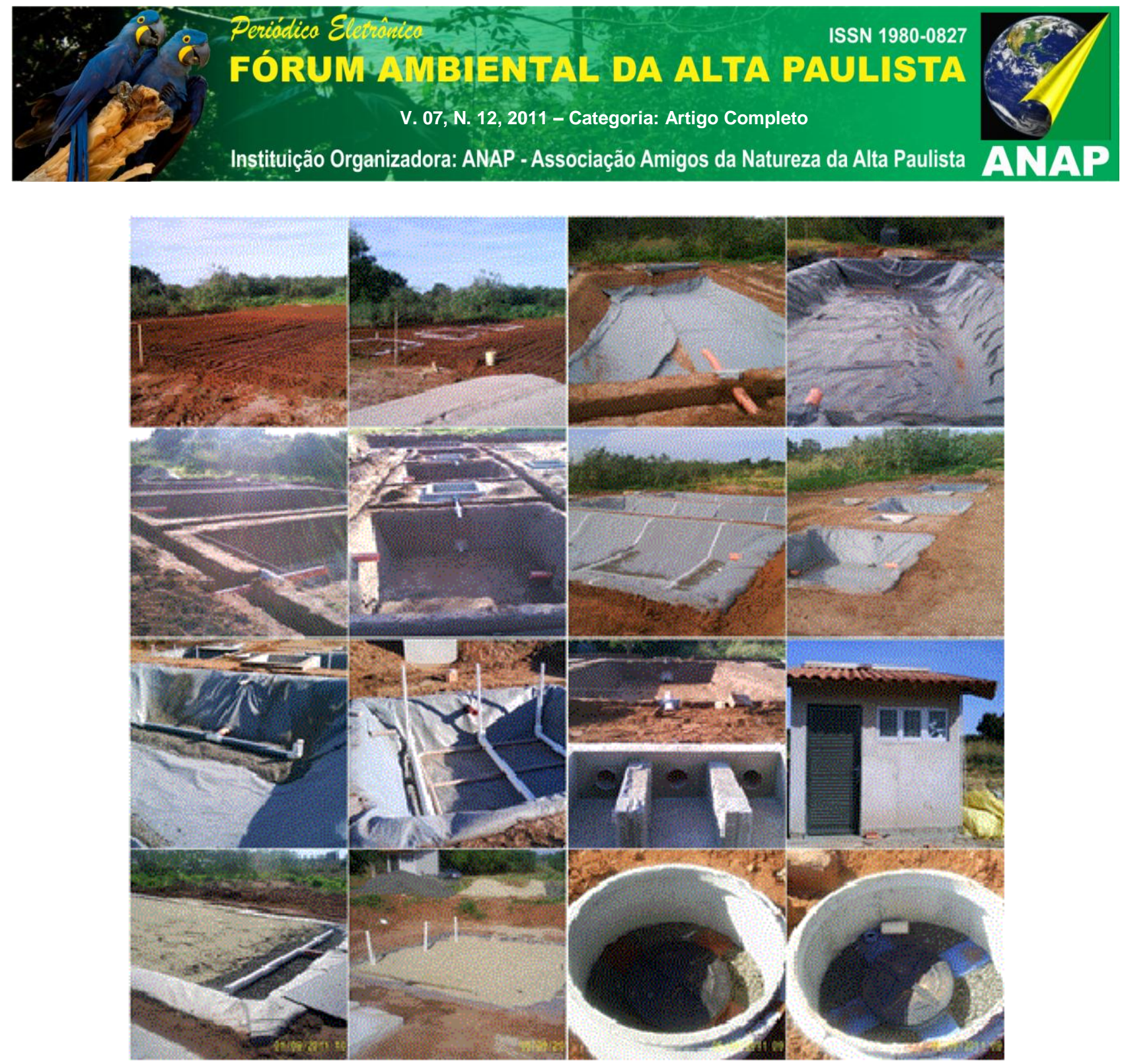

Figura 3. Etapas de construção da ETE.

\section{CONCLUSÃO}

Após cinco messes de obras a Estação de Tratamento de Esgotos foi concluída, devendo entrar em operação já no mês de outubro. Com o final da construção foi possível observar que o orçamento previsto anteriormente foi suficiente para realização de todas as atividades.

Com o processo de recirculação espera-se que a quantidade de oxigênio que adentre o leito seja maior, proporcionando uma melhor condição ao processo de nitrificação e remoção do nitrogênio amoniacal. Recomenda-se que sejam realizadas 


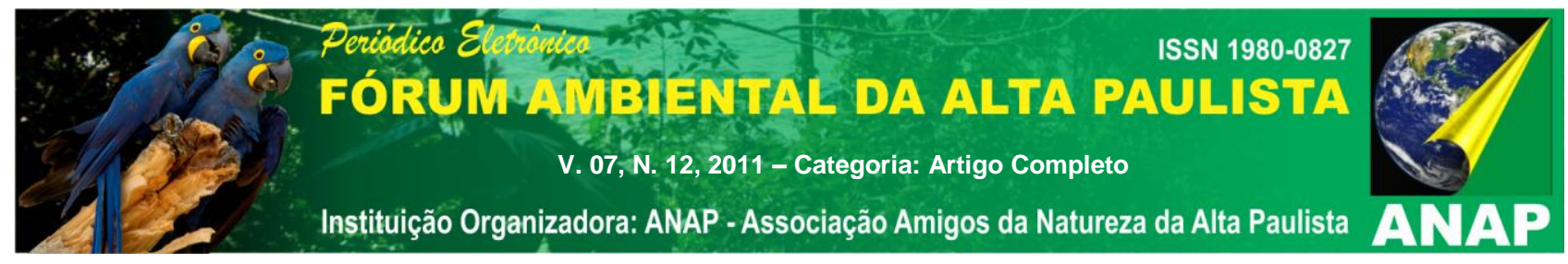

analises físico-química e bacteriológica do esgoto, antes e depois do sistema, para confirmar a teoria de que esse processo proporcionará uma melhor qualidade ao tratamento.

\section{REFERÊNCIAS BIBLIOGRÁFICAS}

EPA- United States Environmental Protection Agency. Constructed Wetlands Treatment of Municipal Wastewaters. Manual. Cincinnati. 165p. Ohio, 2000.

GALVÃO JUNIOR, A. C.; Paganini, W. S. Aspectos conceituais da regulação de serviços de água e esgoto no Brasil. Eng. Sanit. Ambient. v.14, n.1, p. 79-88, 2009.

IBGE - Instituto Brasileiro de Geografia e Estatística. Pesquisa Nacional de Saneamento Básico - PNSB (2008). Rio de Janeiro, 2010.

IBGE - Instituto Brasileiro de Geografia e Estatística. IBGE cidades. Disponível em: <http://www.ibge.gov.br/cidadesat> Acesso em: 15 mai. 2011.

OLIVEIRA, E. L; TALAMONI, J. L. B; ENOKIBARA, M; FILHO, G. S. C; NETO, L. C. Alagados Construídos no tratamento de águas residuárias do Jardim Botânico Municipal de Bauru/SP. In: 23ํㅡㄹ Congresso Brasileiro de Engenharia Sanitária e Ambiental, 2005.

OMS - ORGANIZAÇÃO MUNDIAL DA SAÚDE. The world health report 2007: a safer future: global public health security in the 21st century. Genebra, Suécia, 2007.

SARDINHA, D. S.; Conceição, F. T.; Souza, A. D. G.; Silveira, A.; Julio, M.; Gonçalves, J. C. S. I. Avaliação da qualidade da água e autodepuração do Ribeirão do Meio, Leme (SP). Eng. sanit. ambient. V.13, № 3, p. 329-338, 2008.

SRIVASTAVA, J; KAYASTHA, S; JAMIL, S; SRIVASTAVA, V. Environmental perspectives of Vetiveria Zizanioides (L.) Nash. Acta Physiol Plant. P 413-417. Krakón, 2008. 